J. Biosci., Vol. 3 Number 1, March 1981, pp. 83-88. (C) Printed in India.

\title{
Effect of human chorionic gonadotropin on serum levels of progesterone and estrogens in the pregnant bonnet monkev (Macaca radiata)
}

\author{
A. JAGANNADHA RAO and S. G. KOTAGI and N. R. MOUDGAL. \\ Laboratory of Endocrine Biochemistry, Department of Biochemistry, Indian Institute of \\ Science, Bangalore 560012 \\ MS received 11 November 1980; revised 11 February 1981
}

\begin{abstract}
Administration of human chorionic gonadotropin to pregnant bonnet monkeys (Macaca radiata) at 55-60 days and 130-140 days of pregnancy resulted in a significant increase in serum progesterone levels. This effect could be observed even in lutectomized monkeys. However, no significant change in the serum estrogen level was noticed. These results suggest that although no chorionic gonadotropin is detectable in the serum after 35 days of pregnancy, the foetoplacental steroidogenic system is still responsive to exogenous gonadotropic stimulation.
\end{abstract}

Keywords. Placenta; chorionic gonadotropin; steroidogenesis.

\section{Introduction}

It has been suggested by Neill and Knobil (1972) that in the rhesus monkey, the low levels of chorionic gonadotropin released at the time of and subsequent to implantation is responsible for the transient restoration of the progesterone-secretory function of the corpus luteum of the cycle during very early stages of pregnancy. The decline in the progesterone levels during early pregnancy (by 23-25 days) is suggested to be due to the refractoriness of the corpus luteum to chorionic gonadotropin (Neill and Knobil, 1972). The chorionic gonadotropin level in the serum reaches a peak value by about the 23rd day of pregnancy and decreases rapidly thereafter to an undetectable level by the 35th day (Hodgen et al., 1974; Atkinson et al., 1975). The placental level of chorionic gonadotropin also becomes undetectable, by the 40th day (Hodgen et al., 1975). In spite of the low serum progesterone level (Neill et al., 1969; Bosu et al., 1973) the levels in the uteroovarian and uterine venous system are high (Walsh et al., 1974), suggesting that the serum progesterone level may not be a good indicator of progesterone synthesis in specific tissues during pregnancy. Pregnancy in the bonnet monkey can be terminated upto the 25th day by administration of an antiserum raised to ovine LH or

Abbreviation used: hCG, Human chorionic gonadotropin. 
LH $\beta$ in the monkey (Prahalada et al., 1975; Moudgal et al., 1978). It is also shown that ovareactomy after the $21 \mathrm{st}$ day of pregnancy has no effect on the course of pregnancy (Tullner and Hertz, 1966). These results emphasize that the ovarian function in the maintenance of pregnancy is limited to the first 21 days and that the placenta may be taking over some of the functions of the ovary, especially steroidogenesis. In this paper, we report results which suggest that the placenta in the monkey is responsive to exogenous administration of human chorionic gonadotropin (hCG), by producing progesterone at a time even when endogenous chorionic gonadotropin is not detectable.

\section{Materials and methods}

\section{Chemicals and methods}

Highly purified hCG (9000-10000 I.U./mg) was obtained as a gift from the National Institute of Health, Bethesda, Maryland, USA. Radioimmunoassays of serum progesterone and estrogen were done according to the procedures validated in the laboratory (Prahalada et $\alpha$., 1975).

\section{Animals}

Adult cycling female bonnet monkeys weighing 4-6 $\mathrm{kg}$ each exhibiting three successive regular cycles were employed in the study. The animals were housed in individual cages in rooms with controlled lighting regimen of $12 \mathrm{~h}$ light per day. The menstrual cycles of these monkeys ranged from 25-28 days and the first day of menses was considered as day one of the cycle. Females were exposed to male monkeys of proven fertility for four days (day 10 through 13) of the cycle. Details of the breeding programme and the method of monitoring pregnancy have been described (Madhwa Raj et al., 1974; Moudgal et al., 1974; Prahalada et al., 1975). The animals were fed with pelleted monkey feed from Hindustan Lever Limited, Bombay and water was provided four times in a day. Besides, the diet was supplemented with fresh carrots and bananas every day.

\section{Lutectomy}

Pregnant monkeys (monkey no. 79, 55-60 days and monkey no. 96, 135-140 days) were subjected to lutectomy under intraval sodium (May and Baker, Bombay, 25 $\mathrm{mg} / \mathrm{kg}$ body weight) anaesthesia. The corpus luteum was excised completely by making a half-inch midventral incision. The animals wereallowed a minimum of 8 days' rest before subjecting them to further experimentation.

\section{Injection and bleeding}

Pregnant monkeys were injected intravenously with $1 \mathrm{mg}$ of hCG in sterile saline at 9 A.M. Blood $(5 \mathrm{ml})$ was collected at specified intervals from the femoral vein. Serum was separated and stored at $-20^{\circ} \mathrm{C}$. All monkeys were injected Uniferon with $\mathrm{B}_{12}$ (Glaxo Laboratories, Bombay) during the experimental period to compensate for the loss of blood. Two pregnant monkeys injected $1 \mathrm{ml}$ of $0.9 \%$ sodium chloride served as controls. 


\section{Results}

\section{Effect of hCG during pregnancy}

It can be seen from figure 1 that both the early pregnant monkeys (No. 88, 508) responded to hCG injection by a marked increase (5-7 fold) in serum progesterone reaching a peak value at $6 \mathrm{~h}$. Similarly, the late pregnant monkey (No. 50) also responded to exogenous hCG by an increased serum progesterone level. It can also be seen that serum progesterone levels increased significantly ( 2 to 3 -fold) as early as $2 \mathrm{~h}$.

\section{Effect of lutectomy}

After ensuring that the pregnant monkeys (No. 79 and 96) responded to exogenous hCG, in an identical manner compared to those shown in figure 1, the corpora lutea were excised, hCG administered and the progesterone levels monitored at the time intervals indicated in figure 2. An increase in progesterone levels similar to that observed in the non-lutectomized monkey (figure 1) was observed with these lutectomized monkeys. The peak occurred at $12 \mathrm{~h}$ compared to $6 \mathrm{~h}$ in the normal monkeys.

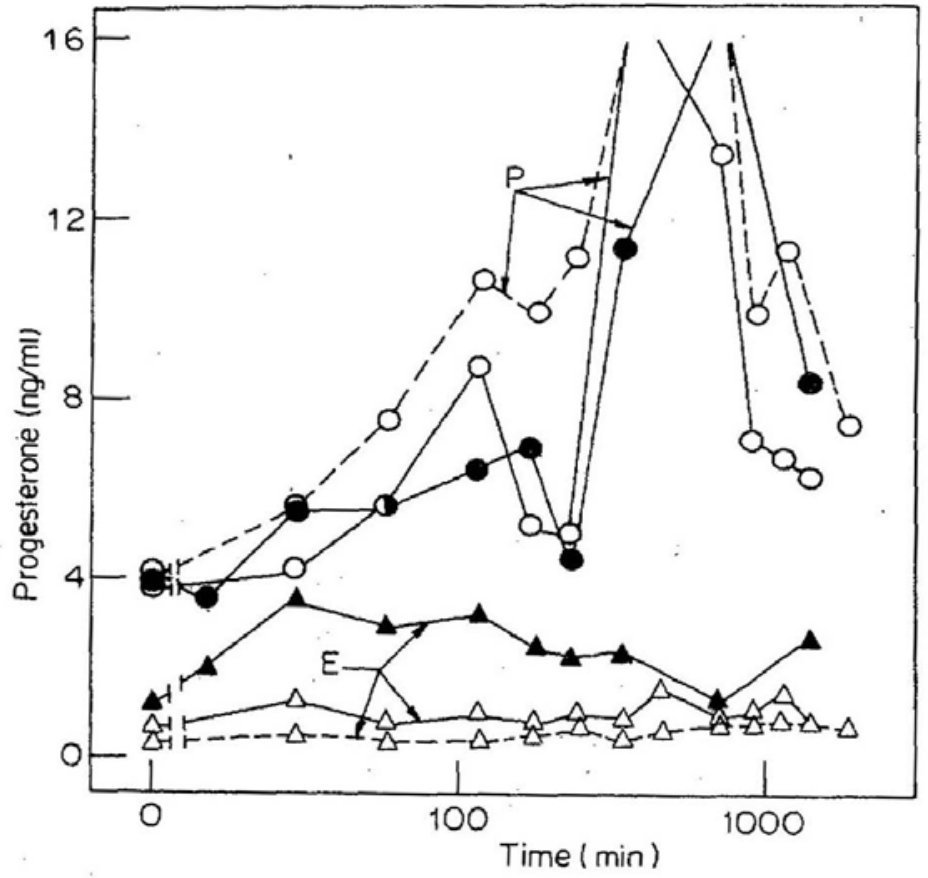

Figure 1. Effect of injection of hcG on serum level of progesterone and estrogens during early pregnancy.

Early pregnancy (Monkey No. 88,508): Progesterone (O), Estrigens $(\Delta)$ Late pregnancy (Monkey No. 50: Progesterone (O), Estrogens ( $\boldsymbol{\Delta}$ ). 


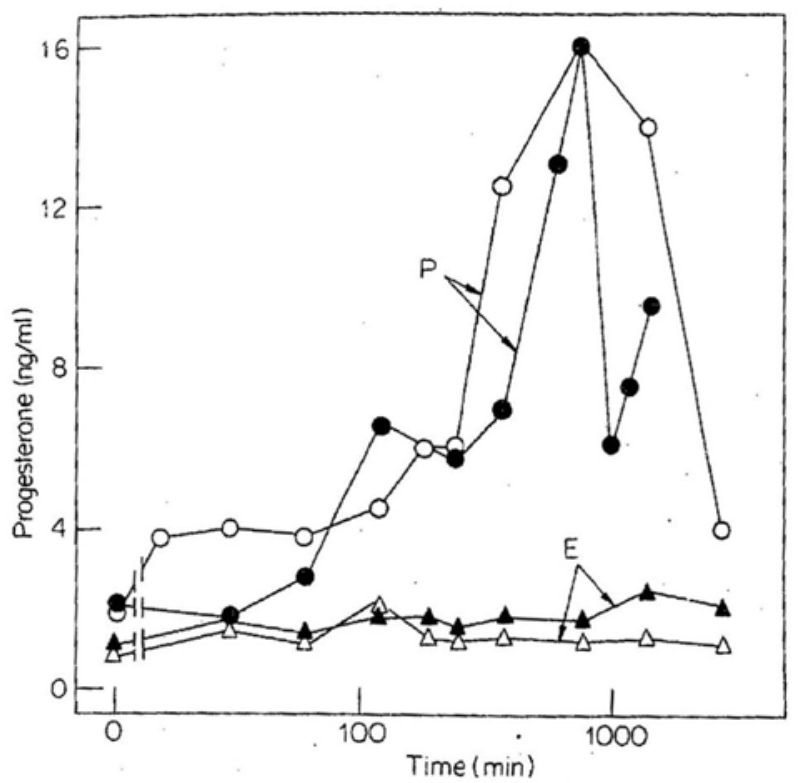

Figure 2. Effect of hcG on serum levels of progesterone and estrogens in leutectomized monkey.

Early pregnancy (Monkey No. 79): Progesterone (O), Estrogen ( $\Delta$ ). Late pregnancy (Monkey No. 96): Progesterone (O), Estrogens $(\boldsymbol{\Delta})$.

One possible explanation for the increased progesterone levels could be the reported diurnal variation in progesterone levels (Bosu et al., 1973). To examine this possibility a control study was carried out by injecting saline instead of hCG and monitoring the progesterone levels (figure 3). It can be seen that the diurnal flutuation is only from 2 to $5 \mathrm{ng}$ compared with 4 to $25 \mathrm{ng}$ in the hCG-treated animals.

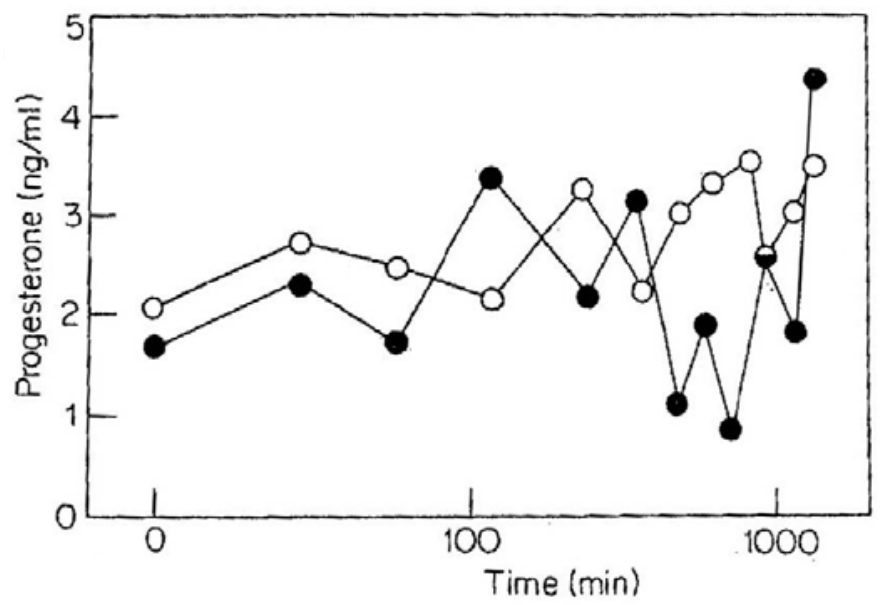

Figure 3. Effect of injection of saline on serum levels of progesterone. Early pregnancy (Monkey No. 79), (O) Late pregnancy (Monkey No. 96), (О). 


\section{Discussion}

It is well known that the corpus luteum is transiently stimulated by chorionic gonadotropin in the monkey and this stimulation is responsible for the increased serum progesterone observed during early pregnancy,. During the late stages, this production of progesterone is taken over by the foetoplacental unit. The large increase in the progesterone level even in the lutectomized pregnant monkeys in response to hCG administration clearly demonstrates that the foetoplacental unit is responsive to exogenous gonadotropin. At this stage of pregnancy the chorionic gonadotropin is not detectable in the serum (Hodgen et al., 1974; Atkinson et al., 1975) and in placenta (Hodgen et al., 1975) and it is not clear how the relatively high progesterone levels are maintained. Though the observation of Hobson (1972 a, b) that chorionic gonadotropin can be extracted from the placenta of 7-25 weeks in rhesus monkey has not been confirmed, it is possible that the placenta may be producing a very small quantity of chorionic gonadotropin not detectable by present methods. Also, such low quantities may be locally sequestered and stimulate steroidogenesis. The results of the present study show that the foetoplacental steroidogenic system of late pregnancy is responsive to exogenous chorionic gonadotropin and lend some support to such a suggestion.

Studies of Ainsworth et al. (1969) suggest that the placenta of the rhesus monkey possesses the enzymatic system required for the conversion of androgen precursors to oestrons and oestradiol as well as pregnenolone to progesterone and other progestogens in vitro. It is known that the biosynthesis of the steroids in the placenta depends on the precursors brought to it from the foetal and maternal compartments and the importance of foeto-placental pathways of steroid biosynthesis in the monkey has not been fully assessed (Bosu et al., 1973). It is suggested that in the monkey, the foetus may be involved in steroid biosynthesis during pregnancy, and the maternal and foetal adrenals may also contribute to steroidogenesis during pregnancy (Bosu et al., 1973). In fact it has been demonstrated in the rhesus monkey that during late pregnancy the foetal pituitary is responsive to exogenous gonadotropin releasing hormone and the gonad responds to hCG with increased testosterone production (Huhtaniemi et al., 1977). Although the results obtained in the present study do not permit us to specify the site of action of hCG, they do suggest that the steroidogenic system of the foeto-placental unit in the monkey is responsive to exogenous hCG at a time when the influence of endogenous chorionic gonadotropin is completely absent.

\section{Acknowledgements}

The authors wish to thank the Family Planning Foundation, World Health Organisation and the Indian Council of Medical Research for financial assistance, and Dr G. S. R. C. Murthy, Dr B. R. Srinath and Mr. B. Shanmughavelu for technical help. The gift of hormones and antisera by NIAMDD, National Institute of Health Bethesda is gratefully acknowledged. One of us (A.J.R.) is a Career Development Awardee of the Family Planning Foundation, India. 


\section{References}

Ainsworth, L., Deenen, M. and Ryan, K. J. (1969) Endocrinology, 84, 1421.

Atkinson, L. E., HotchKiss., Fritz., Surve, A. H., Neill, J. D. and Knobil, E. (1975) Biol. Reprod., 12, 335.

Bosu, W. T. K., Johansson, E. D. B. and Gemzell, C. (1973) Acta Endocrinol., 74, 743.

Hobson, B. M. (1972a) Folia Primal., 18, 35.

Hobson, B. M. (1972b) Folia Primat., 18, 463.

Hodgen, G. D. Tullner, W. W., Vaitukaitis, J. L., Ward, D. N. and Ross, G. T. (1974) J. Clin Endocr. Metab., 39, 457.

Hodgen G.D., Niemann, W. H. and Tullner, W. W. (1975) Endocrinology, 96, 789.

Huhtaniemi, I. T., Korenbrot, C. C., SeronFerre, M., Foster, D. B., Parer, J. T. and Jaffe, R.B. (1977) Endocrinology, 100, 839.

Mudhwa Raj, H. G., Srinath, B. R., Jagannadha Rao, A. and Moudgal, N. R. (1974) Proc. Indian Natl. Sci. Acad., 40, 393.

Moudgal, N. R., Jagannadha Rao, A. and Prahalada, S. (1974) J. Reprod. Fert. Suppl., 21, 105.

Moudgal,N.R., Mukku,V.R.Prahalada, S. ,Murthy, G. S. R. C. and Li, C. H. (1978) Fert. Steril, 30, 223.

Neill, J. D., Johansson, E. D. B. and Knobil, E. (1969) Endocrinology, 84, 45.

Neill, J. D. and Knobil, E. (1972) Endocrinology, 90, 34.

Prahalada,S., Venkatramaiah, M., Jagannadha Rao, A. and Moudgal, N. R. (1975) Contraception, 12, 137.

Tullner, W.W. and Hertz, R. (1966) Endocrinology, 78, 1076.

Walsh, S. W., Wolf, R. C. and Meyer, R. K. (1974) Endocrinology, 95, 1704.

Statement about ownership and other particulars about Journal of Biosciences

1. Place of Publication

2. Periodicity of Publication

3. Printer's Name

4. and 5. Publisher and Editor

6. Nationality

7. Address

8. Name and Address of the Owner

\author{
Bangalore \\ Quarterly \\ S. Ramaseshan \\ Indian Academy of Sciences \\ Bangalore 560080 \\ S. Ramaseshan \\ Indian \\ Indian Academy of Sciences \\ P.B. No. 8005 \\ Bangalore 560080 \\ Indian Academy of Sciences \\ BANGALORE 560080
}

I, S. Ramaseshan, hereby declare that the particulars given above are true to the best of my knowledge.

Date: 1st March 1981

S. Ramaseshan

Signature of Publisher 